\title{
MERCADO COMUM DO SUL: SAÚDE E ENFERMAGEM*
}

\author{
Glaci de Oliveira Pinto Vargas**
}

\begin{abstract}
RESUMO: A discussão e a compreensão sobre as questões que envolvem o MERCOSUL e a abrangência desta realidade tomam-se significativas, pois envolvem todos os segmentos da sociedade. O estudo visa proporcionar aos profissionais de saúde, especialmente aos de Enfermagem, o conhecimento básico sobre o Tratado de Assunção, que envolve a participação dos quatro países do Cone Sul - Brasil, Argentina, Uruguai e Paraguai; objetivos, características, sistemas de saúde dos países integrantes, recursos humanos em saúde e partir para a contextualização da referida área de atuação. A integração vem ocorrendo a passos largos em vários setores, principalmente na área econômica, uma vez que as relações devem consolidar-se em 1995. Neste sentido, a corrida contra o tempo não pode constituir fator imobilizante de outros segmentos. É bem verdade, que alguns grupos de profissionais de saúde e da previdência social mantêm-se atentos e receptivos às iniciativas dos seus setores, ainda que de maneira esparsa e pontual.
\end{abstract}

ABSTRACT: Discussing and understanding all MERCOSUL's issues and its wide range reality is definitely relevant since it embodies every segment of society. The preliminary study is meant to provide for healt professionals, mainly the nursing, basic data on the tratado de assunçăo - a Treaty signed by Brazil, Argentina, Uruguay and Paraguay which form the so called CONESUL - defining objectives, peculiarities and welfare facilities as well as their work field. The integration has already started on. Actually we can assume that it has been effective on the part of economics, yet all its relations are to consolidate in 1995. Nevertheless that should not prevent all segments from moving. As a matter of fact, being aware and open to any initiative from their peers, some of the welfare practitioners have tried to stand by then even though in a rather haphazard way.

\section{UNITERMOS: Mercosul - Saúde - Enfermagem}

\section{INTRODUÇÃO}

O MERCOSUL surgiu devido a mudanças no mundo. As nações, que até então viviam isoladas umas das outras, começaram a juntar-se em grupos para criar alianças de vários tipos: políticas, econômicas, sociais. A união pioneira, que entusiasmou outras, como a do MERCOSUL, começou no continente europeu. A Europa tornou-se hoje uma "grande nação", com a criação da Comunidade Econômica Eu- ropéia (CEE). Com essa união, os países europeus ganharam unidade e se fortaleceram para competir no comércio intemacional.

Assim, os países do Cone Sul seguiram o exemplo, e através de seus govemantes e parlamentares decidiram pela união para seu fortalecimento: criando para si suas próprias defesas internas, nas quais ajudar-se-ão uns aos outros, essas nações começaram uma cooperação para o desenvolvimento científico e tecnológico.

\footnotetext{
* Trabalho apresentado como Tema Livre no $45^{\circ}$ Congresso Brasileiro de Enfermagem. Olinda-Recife - PE, 28 de novembro a 3 de dezembro de 1993.

** Mestre em Educação, pesquisadora e coordenadora da Divisão de Pesquisa e Documentação da Escola de Saúde Pública/SSMA-RS. Prof essora Adjunta do Curso de Enfermagem da Universidade Luterana do Brasil/Canoas-RS.
} 
Surgiu entåo, em 26 de março de 1991, o "Tratado de Assunça”" que deu origem ao MERCOSUL, assinado na capital paraguaia pelos presidentes Fernando Collor de Mello (Brasil), Carlos Menem (Argentina), Luis Aberto Lacalle (Uruguai) e Andrés Rodriguez (Paraguai).

A constituição do Mercado Comum do Sul Brasil, Angentina, Uruguai e Paraguai - está destinada a mudar a geografia econômica mundial, com o surgimento da maior massa territorial fértil de que o homem tem noticia, onde naturalmente a agricultura - e næ̉o a indúctria - será a atividade principal e pioneira.

Se o Brasil conta com cerca de $10 \%$ da terra arável do planeta, a soma de sua superfície com os territórios da Argentina, Paraguai e Uruguai dará lugar ao exercício da maior potência agrícola da história da civilização, cobrindo um mesmo espaço que compreende quatro climas distintos: um escancaradamente equatorial, no norte; um tropical entre o sul de Tocantins e o norte do Paraná; outro subtropical, entre Paraná e Santa Catarina, abarcando o Paraguai e o norte da Argentina e um extenso segmento temperado, entre o Rio Grande do Sul, o Uruguai e a Patagônia.

Essa condição geográfica excepcional dá garantia de apreciável produção agrícola, pois afasta as consequências dos fenômenos climáticos indesejados quando no Sul: o excesso de chuvas, por exemplo, compromete a atividade rural, o norte ou a zona tropical assegurarảo o abastecimento. Por outro lado, ainda que a Argentina e Uruguai, em consequência de sua longa e rasa plataforma continental, e o mediterrâneo Paraguai, não tenham ou venham a ter grandes portos, estes nảo são problemas para o Brasil, que os tem em profusão, para oferecer aos parceiros. Atualmente, dispõe de quatro dos dez mais importantes portos do mundo: Rio Grande, no Rio Grande do Sul, com capacidade para navios de até 100 mil toneladas de carga líquida; Paranaguá, no Paraná para $65 \mathrm{mil}$ toneladas; Vitória, no Espírito Santo - que é dos maiores complexos portuários do mundo - para 350 mil toneladas e ponta da Madeira, em São Luís do Maranhāo, para outras 350 mil toneladas.

Além disso, o Brasil vem utilizando as chamadas cargas combinadas - conjugando o minério de ferro, que pesa muito e vale pouco, com o grão agrícola, que pesa pouco e vale muito, e, usando grandes navios para roduzir a distância até as nações importadoras de seus produtos.

Essa visão em relação ao produto agrícola e dos transportes leva naturalmente a uma especulação, que se torna realidade na medida em que o mundo avança na disputa pela industrialização. O Brasil e os demais membros do MERCOSUL terão duas oportunidades, da agricultura e da indústria, para tomar-se independentes de outros países, a năo ser para a exportação de produtos que não cabem com naturalidade em outras regiớes do planeta (Japão, Ásia Oriental). Neste sentido, pode-se afirmar que o MERCOSUL tem o essencial para concorrer com vantagem invencível no mercado internacional de grãos, da terra abundante à logística do armazenamento, transporte e distribuição, se conjugados esforços, Estado e iniciativa privada, dos dois lados do Rio da Prata.

\section{ANTECEDENTES HISTÓRICOS DO MERCOSUL}

O marco fundamental do processo de integração foi definido através da Declaração Conjunta de Iguazu, em 30 de novembro de 1985, assinada pelos Presidentes José Sarney e Raul Alfonsin. Nessa declaração expunham a urgente necessidade da América Latina reforçar seu poder de negociação com o resto do mundo, ampliando sua autonomia, minorando a vulnerabilidade e acima de tudo, afirmando a decisão de conjugar e coordenar esforços dos respectivos governos para revitalizar as políticas de cooperação e integração das nações Latino-Americanas.

Os propósitos contidos na Declaração de Iguazu tomaram-se realidade com a assinatura da Ata para a Integração Argentina-Brasil em 20 de julho de 1986. Através deste documento, foi criado o Programa de Integração e Cooperação Econômica (PICE), cuja meta básica consistia na convocação das comunidades envolvidas para o esforço comum, na promoção de um crescimento de conteúdo moderno - o de encontrar soluções para superação dos modelos tradicionais adotados. Este Programa de Integração e Cooperação Econômica tinha por objetivo propiciar a modemização tecnológica e maior eficiência na aplicação de recursos nas duas economias, através de tratamentos preferenciais ante terceiros mercados, e a harmonização progressiva de políticas econômicas com o objetivo final de elevar o nível de renda e de vida das populaç⿸̃es dos dois países.

Para alcançar estes objetivos foram protocolados vários acordos em diferentes níveis como: Bens de Capital, Abastecimento Alimentar, Expansão do Comércio, Empresas Binacionais, Assuntos Financeiros, Fundo de Investimentos, Transporte Terrestre, Transporte Marítimo, Comunicações, Cultural, Administração Pública, Moeda, Indústria Automobilística, Indústria de Alimentação, Fronteira Regional. 
A adesão do Unuguai ao processo de integração começou quando os três Governos discutiram em Brasília as modalidades de importação deste país no processo de integração e cooperação econômica entre Argentina e Brasil.

Em 30 de novembro de 1988, na cidade de Buenos Aires, foi formulada a Decisão tripartite n 01, e a partir desta decisão, o Unuguai passou a participar de alguns protocolos dos programas de Integração e Cooperação Econômica.

Em 10 de dezembro de 1986 foi assinada a Ata da Amizade Argentina-Brasil pela Democracia, Paz e Desenvolvimento e em 29 de novembro de 1988, o Tratado de Integração, Cooperação e Desenvolvimento entre a República da Argentina e a República Federativa do Brasil, que retificam o andamento do programa de Integração e Cooperação Econômica (PICE) e, ao mesmo tempo, incorporaram e criaram mecanismos para acelerar o processo de integração.

$\mathrm{Na}$ Ata da Amizade, os governos reafirmavam o propósito de abrir novos horizontes para a cooperação e integração regional, conscientes de que o crescimento econômico é condição necessária para a justiça social, a consolidação da democracia e da paz.

No Tratado de 1988 , baseados na avaliação positiva do Programa de Integração e Cooperação Econômica, argumentavam a necessidade de consolidar definitivamente o processo de integração econômica entre as duas nações, como marco de renovado impulso à integração da América Latina.

É importante salientar, que a partir da assinatura desse Tratado, aprovado pelos congressos dos dois países em agosto de 1989, os temos do processo de integração se modificam. A integração deixou de ser um dese jo político dos governantes, para transformarse numa realidade política, econômica e social das sociedades.

Em 16 de março de 1990, os novos governantes da época, Carlos Menem e Fernando Collor de Mello, ratificaram o Processo de Integração em andamento com a criação da comissão de Execução do Tratado de Integração, Cooperação e Desenvolvimento, quando designaram os seus respectivos membros.

A Ata de Buenos Aires, assinada pelos presidentes da Argentina e do Brasil, em 06 de agosto de 1990, estabelecia um Mercado Comum entre estes países, com prazo para a conformação definitiva fixado em 31 de dezembro de 1994.

Para cumprir o estabelecido, foi criado o Grupo Mercado Comum, com a função de elaborar as medi- das que permitissem dar cumprimento aos objetivos e prazos adotados pelos presidentes de ambos os países.

Nos dias 21 e 22 de agosto de 1990, reuniram-se no Rio de Janeiro, as delegações brasileira e argentina para elaboração de uma proposta conjunta, no sentido de objetivar as metas emanadas da Ata de Buenos Aires.

A primeira reunião do Grupo Mercado Comum Argentina-Brasil foi realizada nos dias 3 e 4 de setembro de 1990, na cidade de Buenos Aires. Ao analisar as propostas formuladas pelas duas delegaçðes no Rio de Janeiro, chegaram à conclusão de que a coordenação e harmonização da política econômica deveria ser tomadas como metas prioritárias.

Para dar início ao dito processo, decidiu-se criar sub-grupos técnicos de trabalho para analisarem as políticas macro-econômicas e setoriais.

Nos dias 05 e 06 de setembro de 1990 foi apresentado às delegações do Unuguai e do Paraguai o andamento do processo de integração Argentina-Brasil. Nessa ocasião, as duas delegações referidas expressaram e expuseram a vontade de seus governos em participar da integração do Mercado Comum e posteriormente, encaminharam negociações para a elaboração de um acordo quadripartite.

Com a participação das delegaç̃̃es da República do Paraguai e da República Oriental do Unuguai, na qualidade de observadores, reuniu-se nos dias 22 e 23 de outubro de 1990, no Rio de Janeiro, o Grupo Mercado Comum Brasil-Argentina, para exame dos trabalhos encomendados aos sub-gnupos técnicos.

Nos dias 13 e 14 de dezembro de 1990, na cidade de Buenos Aires, reuniu-se o grupo Mercado Comum Argentina-Brasil para uma avaliação dos resultados alcançados desde 06 de julho de 1990, quando foi firmada a Ata de Buenos Aires (estabelecimento do Mercado Comum entre Argentina e Brasil). Com a presença das delegações do Unuguai e Paraguai, o Grupo Mercado Comum registrou a finalização do Acordo de Complementação Econômica entre Argentina e Brasil.

Posteriormente, em 20 de dezembro de 1990, era firmado novo Acordo de Complementação Econômico (ACE-14), que consolidado e ampliado num único texto, continha todos os Acordos Bilaterais já firmados, além das regras para o estabelecimento do Mercado Comum em seus aspectos comerciais, até 31 de dezembro de 1994.

Este Acordo foi assinado em 26.12.90, com base 
no Tratado de Montevidéo-80, que criou a ALADI Associação Latino-Americana de Integração, e entrou em vigor na data de sua publicação, em 18 de março de 1991, através do Decreto ${ }^{\circ} 60$ de 15.03.91, que dispunha sobre a sua execução.

Essa trajetória, apresentada em linhas gerais, culminou com a assinatura do Tratado de Assunção de 26 de março de 1991, que criou o Mercado Comum do Sul (MERCOSUL) e consolidou as iniciativas do Brasil e Argentina, com posterior adesão do Unuguai e Paraguai.

\section{O MERCOSUL E SEUS PRINCIPAIS OBJETIVOS}

- Ampliar as possibilidades para que os países aumentem sua produtividade, o que na linguagem econômica, chama-se de "economia de escala". Esta permite que se conquiste maior competitividade no comércio internacional, pelo aumento da produção de bens.

- Melhorar a qualidade da of erta de bens e serviços. Esta medida garante produtos mais qualificados para os países, e uma prestação de serviços mais elaborada.

- Estimular o fluxo do comércio conı o resto do mundo. Isso dá conảıç̃̃es aos países de atraírem investimentos estrangeiros para suas economias.

- Abrir a economia dos quatro países, buscando-se assim estimular a participação de outros países da América do Sul no MERCOSUL. Abrir a economia significa, por exemplo, diminuir restrições à entrada de produtos de outras nações e reduzir ou acabar com impostos sobre esses produtos.

- Definir o papel dos setores privados e da sociedade no MERCOSUL. Quer dizer que o setor privado (empresários) e a sociedade como um todo, como maiores beneficiários e interessados na integração dos países, precisam participar de forma ef etiva do processo.

- Dar condições a cientistas e técnicos brasileiros, argentinos, uruguaios e paraguaios para que possam desenvolver pesquisas, apresentar produção científica e promover intercâmbio de co.lhecimentos. Isto possibilita o desenvolvimento aos vários setores e leva conseqüentemente, à cr mpetição inte nacional e ao crescime ito do produc interno bruto (PIB).

\section{Características do Mercado Comum do Sul}

- Livre circulação de bens e serviços e de fatores produtivos entre os países integrantes.

- Estabelecimento de uma tarifa externa comum, adoção de uma política comercial comum em relação a terceiros Estados, ou grupamentos de Estados, e a coordenação de posições em foros econômicos, sociais, regionais e internacionais.

- Coordenação de políticas macro-econômicas e setoriais entre os Estados-Partes - de comércio exterior, agrícola, industrial, fiscal, monetária, cambial e de capitais de serviços, alfandegária, de transporte, comunicaçð̃es e outras.

\section{Resultados Gradativos}

Unidos pelo MERCOSUL, os quatro países vão representar uma potência. Sua população somada, será de 189 milhões de habitantes aproximadamente. Já o seu território aumentará para 12 milhỏes de quilômetros quadrados e sua economia, em estágio de cooperação, vai produzir um Produto Interno Bruto acima de 411 bilhões de dólares (moeda norte-americrina). Este PIB de US\$411 bilhões foi calculado para 1992. iNo entanto, depiois da integração efetiva entre os países, este número deverá aumentar, pelo fortalecimento natural de suas economias.

Porém, a ef etivação desses resultados será gradativa, na medida que os entendimentos sejam exequíveis e as tratativas colocadas em prática. A exemplo disto, pode-se colocar o que ocorre em relação a:

TRÂNSITO LIVRE: hoje, só se pode atravessar a fronteira entre os países, assinando documentos na alfândega. Em breve será possível apenas apresentando a carteira de identidade. Também, está em estudo a possibilidade dos cidadãos de um país poderem trabalhar no outro. Atualmente isso é proibido por lei, a não ser que a pessoa se naturalize.

TARIFA ÚNICA: cobrança da mesma tarifa de importação sobre os produtos nos negócios com outras nações, evitando que haja competição entre eles, com prejuízo de uns para os outros. Já as tarifas de importação entre os países do acordo deixarão de existir, facilitando assim o trânsito dos produtos e di$r$ inuindo o custo das transações.

Correio INTEGRado: os países estão tendo um sistema de entrega de cartas e encomendas mais rápido e eficiente. Cartas que demoravam dez dias para chegar a seu destino, levam agora apenas dois. 
TRANSPORTE ADEQUADO: a proposta é harmonizar os sistemas de transporte dos quatro países. Assim, os trilhos da viação férrea deverão apresentar dimensões idênticas para evitar a transferência do carregamento de um país para outro e a conseqüente morosidade $\mathrm{e}$ aumento de custos.

Parlamento Único: a proposta que deve ser aprovada em breve, estabelece que os países unificados, além de seus próprios parlamentos, passarão a ter um parlamento comum.

\section{SISTEMAS DE SAÚDE NOS PAÍSES DO MERCOSUL}

O setor saúde - limitado em sua capacidade de financiamento mediante o excessivo gasto público, com baixa representatividade para definir políticas sociais que acompanhem o planejamento do sistema desenvolvido, formando parte de um Estado questionado em sua capacidade como administrador e provedor direto dos serviços - enf renta cada vez maiores dificuldades para propor, liderar e assegurar o acesso aos serviços de saúde a toda população.

A atual crise econômica segue expondo a vulnerabilidade dos modelos de desenvolvimento implantados nos países integrantes do Mercado Comum do Sul nas últimas décadas. Ao mesmo tempo, fortalecem-se as tendências democratizadoras com ascensão ao poder de governos comprometidos em reverter, pelo menos em parte, as desigualdades existentes e agudizadas pela crise. Entretanto, é importante salientar que, se por um lado, as condiçōes parecem favoráveis à colocação de políticas sociais mais progressistas, por outro, permanecem muitos obstáculos que limitam as possibilidades de êxito dos governantes e grupos sociais interessados em um processo de desenvolvimento mais eqüitativo.

Os países que integram este grupamento apresentam entre si marcadas dif erenças, que se refletem na diversidade dos processos seguidos para a implantação dos Sistemas Locais de Saúde. Essas diferenças vão desde a forma de governo (Federativa na Argentina e no Brasil, unitária no Paraguai e Unuguai), passando pela extensão territorial, tarnanho da população, até a economia, a educação, a política, entre outras

Alguns dos municípios destes países tem adquirido um peso relevante no âmbito nacional, afirmando-se pelo volume de suas economias, tamanho da população, importância cultural e política de suas organizaçðes sociais, ou pelos con junto de todos estes fatores.
Por estas condições, conseguem desenvolver sistemas de saúde organizados e administrados pelo governo municipal com apreciável grau de autonom lia e autosuficiência política, financeira e administrativa. Entretanto, a maioria dos municípios não tem a mesma sorte.

A Argentina, a partir de 1985, repensando a função do Estado, vem usando como estratégia a descentralização e a participação da população, procurando assim democratizar e modernizar os seus serviços básicos de saúde. No setor saúde, é empreendida uma política de federalização, que implica em dar apoio às províncias para que estabeleçam, em suas respectivas jurisdições, sistemas integrais de saúde.

Deste modo, tem apresentado experiências bem sucedidas de administração local de sistemas de saúde.

O Paraguai vem realizando uma série de atividades coordenadas pelo Conselho Nacional de Saúde, que partindo da regionalização e da programação local, busca integrar os seus serviços de saúde. Essas atividades facilitam a definição de áreas de responsabilidade e das redes de serviços, elementos significativos para o estabelecimento dos Sistemas Locais de Saúde, que favorecem os processos de descentralização do nível central. Tem definido dezesseis regiōes sanitárias que servem como base para os Sistemas Locais de Saúde.

No Uruguai, a partir de 1985, o Ministério de Saúde Pública tem reorientado suas atividades com base na atenção primária.

Em 1987 foi criada a Administração de Serviços de Saúde do Estado (espécie de uma secretaria, se comparada com a nossa realidade), que se ocupa da administração e gestão dos serviços de saúde, assim como a coordenação dos serviços privados, sendo que a legislação uruguaia faculta a este órgão transferir a responsabilidade dos serviços de saúde aos municípios, o que já é verificado em alguns dos dezenove departamentos do país e também em bairros do departamento de Montevidéo.

Lá. o Ministério da Saúde Pública tem a responsabilidade de formular a política de saúde, normatizar, supervisionar e controlar o setor.

Ainda que reconhecida a individualidade desses processos nacionais nos países do MERCOSUL, todos eles têm procurado transformar o sistema de serviços de saúde com base na estratégia da atenção primária, utilizando como instrumento a descentralização e a implantação dos Sistemas Locais de Saúde. 
Porém, a cobertura ainda se dá por mecanismos da extensão clássica de serviços, e a responsabilidade de atenção à população, em níveis variáveis, apresentase a cargo de serviços não estatais.

\section{Recursos Humanos Em Saúde}

O setor saúde apresenta uma importância nada desprezivel quanto a sua capacidade geradora de emprego.

O conjunto de trabalhadores, direta ou indiretamente, relacionados com a prestação de serviços de saúde, representa uma fração cada vez maior do total da força de trabalho destes países. Por conseguinte, faz-se necessário melhorar os sistemas de informação e as bases de dados sobre os recursos humanos, tanto em termos quantitativos como qualitativos, pois a precariedade destes dados dificulta em muito a análise adequada dos recursos humanos em saúde.

Para tornar mais claras estas colocaçð̃es, pode-se afirmar que foram consultadas inúmeras instituiçð̃es oficiais, variáveis dependendo do país em foco diversos ministérios, consulados, universidade, departamentos de saúde, associaçð̃es de classe, escolas de enfermagem - sem obter respostas ou obtendo com informaçð̃es pouco precisas.

\section{A Enfermagem Especificamente}

A análise da situação da oferta atual denota uma deficiência absoluta e relativa do número de enfermeiras, enfenneiras licenciadas e das outras categorias da enfermagem, que apresentam denominações um pouco diversas de país para país.

Isto constitui um paradoxo, uma vez que a meta almejada, são as ações de atenção primária realizadas por equipes de saúde e não somente por médicos. Em 1989, a Argerisina e o Brasil apresentavam uma proporção menor que 0,5 de pessoal de enfermagem por cada médico. A baixa participação de enfermeiras no conjunto de trabalhadores de saúde não se deve a um problema da of erta destas profissionais, mas da expansåo dos serviços de saúde baseados num modelo centrado no profissional médico. Nos países do MERCOSUL, o pessoal auxiliar e o não qualificado (atendentes de modo geral) constituem numericamente a maior força de trabalho da enfermagem.

É escassa a informação e também a atualização de dados acerca dos profissionais de saúde.
Os dados disponiveis quanto à formaçāo de enfermeiras mostram uma tendência mais ou menos definida.

OBrasil, por exemplo, apresenta uma diminuição em números absolutos de graduados, embora o número de escolas de enfermagem demonstre um aumento importante em todos os países da região.

Esta diminuição do crescimento de graduados em enfermagem, que ocorre também em outras áreas medicina, odontologia - resulta de uma série de fatores, tais como; políticas educacionais, mercado de trabalho saturado, desvalorização da profissão, trabalho assalariado, surgimento de novos cursos, alto custo da formação acadêmica.

Em relação ao aspecto qualitativo da formação em enfermagem, tem-se observado mudanças nos marcos conceituais educativos, no sentido de levar o estudante à comunidade. Todavia, constata-se ainda modelos curriculares ajustados ao tradicional, predominando a hegemonia da formação para a assistência curativa, eminentemente executada no ambiente hospitalar.

Um fato importante a considerar nos países que integram o MERCOSUL relaciona-se às escolas de enfermagem estarem incorporando-se às universidades, processo relevante, pois exige dos docentes uma melhor preparação em diferentes aspectos, como são o dirático-pedagógico e a busca de cursos de pós-gradus ão.

A fim de ativar a of erta de profissionais de enfermagem, tanto a Organização Panamérica de Saúde (OPS) como a Organização Mundial de Saúde (OMS), têm aprovado resoluçð̃es que exortam aos países a valorizarem tal profissão, tanto econômica como socialmente. Ainda assim, constata-se que os países em referência, seguem com trabalhadores não qualificados como a maior força de trabalho em enfermagem ( $70 \%$ do total no Brasil e na Argentina), enquanto os profissionais encontram- $i$; concentrados nos grandes centros urbanos e nos serviços especializados.

A preocupação com os problemas derivados da atual crise tem gerado um grande interesse especial em conhecer as formas em que se inserem as diferentes categorias de profissionais da saúde no mercado de trabalho. Para a enfermagem a forma mais comum de inserção é o contrato assalariado em instituições públicas e/ou privadas. Entretanto, a diminuição dos salários resulta na busca de multi-empregos (diferentes ramos de atividades), ou o acúmulo de empregos na mesma área, como estratégia de sobrevivência, o 
que traz graves conseqüências para o indivíduo e para o exercício do trabalho em saúde.

\section{CONSIDERAÇÕES FINAIS}

Os especialistas e profissionais da saúde começam a entender que é preciso definir um modelo de saúde e previdenciário para os países que integram 0 Mercado Comum do Sul. Para isto, ño basta adaptar a legislação de cada país. É imprescindível avaliar as características sócio-econômicas, os aspectos demográficos e o estágio do processo produtivo para possibilitar um processo, reconhecidamente longo até a obtenção de processo nessas áreas.

Se para a consolidação do esforço de integração que avança nessa parte do continente é essencial a vontade política dos governos das naçðes signatárias da Ata de Assunção, igualmente fundamental é a mobilização das comunidades, que por sua localização geográfica estão diretamente envolvidas no processo. Os acordos e protocolos firmados pelos mandatários dos países integrantes do MERCOSUL representam apenas a moldura jurídico-instituicional indispensável à formalização do bloco regional. Lentos contudo, serão os processos deste mercado em estruturação, se as lideranças políticas, entidades de classe e profissionais, não tomarem a si a tarefa de dinamizá-lo.

O extraordinário volume que alcançou em 1992 e 93 o intercâmbio comercial, é seguro indicativo de que a integração adquiriu força própria. Mas, é necessário conferir-lhe substância, a partir de outros eventos e empreendimentos concretos que reafirmem a identidade de propósitos e revigorem projetos compartilhados, tanto no âmbito municipal, estadual como federal.

Deste modo, os profissionais e as entidades de classe devem alertar-se, pois as questões de saúde, previdência social, educação, bem como outras decorrentes delas, estão sendo colocadas em segundo plano nas discussões do MERCOSUL.

É prioritária a integração, se realizada de forma ampla e irrestrita a todas as áreas. A menos de três anos do início da plena vigência, urge que se vençam as resistências burocráticas que ainda retardam o processo, que deve corresponder a elevados interesses políticos e sociais deste país e de seus sócios.

Para tomar mais prático o planejamento, a execução e a avaliação em torno do debate das questð̌es relativas à saúde, enfocando a enfermagem, por ser motivo deste estudo, propõe-se:

- Criação de comissão para tratamento e reestruturação interna da legislação interna dos países visando a efetiva integração na área da saúde.

- Viabilização do intercâmbio científico, bem como, o encaminhamento das questð̃es educacionais, trabalhistas, sociais e relativas ao aprimoramento de profissionais nos quatro países (Brasil, Argentina, Unuguai e Paraguai).

- Estabelecimento de grupos de estudo sobre a qualificação e quantificação dos diversos profissionais da área, para as diversas regiôes do MERCOSUL.

- Envolvimento das entidades de classe, instituições públicas e privadas, para a proposição de políticas e prioridades para a formação de pessoal técnico e auxiliar para a saúde.

- Análise das ações de saúde e características específicas regionais para implantação e implementação de cursos de graduação e de nível médio.

- Promoção de educação continuada em saúde, vista em três ângulos:

- reciclagem em serviços.

- continuidade de estudos de educação formal (graduação e pós-graduação);

- núcleos de estudos por áreas de interesse.

- Participação das entidades de classe e/ou profissionais da enf ermagem em fóruns a respeito das questões da saúde no MERCOSUL.

- Estabelecimento de grupos de estudo sobre a inserção no mercado de trabalho, valorização econômico-financeira e social dos profissionais de enfermagem.

- Promoção de eventos internacionais, nacionais e regionais para valorização do trabalho da enfermagem, redimensionamento de profissionais, divulgação das competências e do desempenho profissional. 


\section{BIBLIOGRAFIA}

1. CARVALHEIRO, José da Rocha. A saúde e o MERCOSUL Săo Paulo/USP: Instituto de Estudos Avançados, 1991. (mimeo)

2. ORGANIZAÇÃO PANAMERICANA DE SAÚDE. Las condiciones de salud de las Americas. Washington, D.C. OPS, 1990.
3. BORGES, Leticia. MERCOSUL, Caminho sem volta. Revista doMERCOSUL, julho, 1992

Recebido para publicação em 4.12 .93 